\title{
OPTIMIZATION AND ANALYSIS OF STAFFING PROBLEMS AT A RETAIL STORE
}

\author{
Kanna Miwa \\ Nagoya Gakuin University \\ School of Commerce \\ Atsutanishimachi, Atsuta-ku, Nagoya, Aichi, \\ 456-8612, JAPAN
}

\author{
Soemon Takakuwa \\ Nagoya University, Graduate School of Economics \\ and Business Administration \\ Furo-cho, Chikusa-ku, Nagoya, Aichi, \\ 464-8601, JAPAN
}

\begin{abstract}
In this study, a simulation modeling procedure for a retail store was proposed to find the optimal number of clerks based on operation types, operation frequency, and staffing schedule. First, all required data for staffing problems were collected and work loading was performed during each 24 -hour period. Then, integer programming was used to obtain an initial feasible solution. Finally, simulation experiments were performed together using OptQuest, and optimal solutions were obtained. The proposed procedure was applied to the actual case. It was found that the staffing problems can be solved easily and effectively.
\end{abstract}

\section{INTRODUCTION}

In this study, a simulation model was constructed and used to examine staff scheduling with particular attention to customer wait times at the cash register at a retail store. All operations performed by clerks were carefully examined to determine staff scheduling at the retail store on campus at Nagoya University. All required data for staffing problems were collected, including the point of sales (POS) data and time study data for all clerks, with reference to the company manuals.

POS software is usually recognized for use with merchandizing, in-store merchandizing, and operations (Tajima 2001). In-store merchandizing consists mainly of space allocation, planograms, and in-store promotions. In this study, in-store merchandizing and operations were treated as a model and used to analyze customer flows and congestion in retail stores. Problems related to personnel scheduling have been studied for many years due to the importance of planning to the overall performance of a business in terms of service quality provided to the customer and cost to the organization. For instance, Takakuwa and Okada (2005) suggested that simulation modeling in conjunction with integer programming and direct-search methods can be used for operations planning for an inbound call center to minimize personnel expenses. Takakuwa and Wijewickrama (2008) developed a discrete-event-simulation to optimize doctor schedules in all departments of an outpatient hospital ward at the Nagoya University hospital. Wijewickrama and Takakuwa (2004) presented a simulation analysis of patient flow aiming to shorten wait time by identifying an optimum doctor mix. The objective of all of the above studies was to minimize personnel expenses or achieve increased satisfaction with service levels. In this decade, POS system use has quickly spread among Japanese retailers because it is an accurate data management system that can be used to respond more accurately and quickly to sales trends. As the competition in the retail industry increases, retailers are becoming more and more obligated to optimize their store performance. Simulation has become a widely accepted tool for analyzing performance in the service industry. Several studies have 
focused on various issues related to POS data. Miwa and Takakuwa (2008) presented a simulation modeling procedure for in-store merchandizing to examine customer flows in retail stores. At present, the review of the literature indicates that no studies of personnel planning have been conducted using POS data. The purpose of this paper is different from that of previous research because a simulation-based approach is developed to optimize personnel planning of a retail store using actual POS data. This paper discusses a simulation IP-based approach to optimizing a retail store's personnel planning, especially by making use of POS data. First, during the past two years, POS data was carefully reviewed to analyze the frequency with which customers came into the store. Thereafter, based on the correlation coefficients of the data, several customer frequency patterns were established. Then, a stepwise procedure for personnel scheduling was proposed. Simulation modeling was used together with integer programming to minimize total personnel expenses.

In this study, the work load for all operations in every time period is examined in terms of man-hour; hence, work loading is performed in relation to time elapsed during each 24-hour period during the first stage. Then, integer programming is adopted to obtain an initial feasible solution to staffing problems. Finally, simulation experiments are performed together with OptQuest, and optimal solutions are obtained.

\section{DESCRIPTION OF THE RETAIL STORE}

\subsection{General Operations}

FamilyMart is a convenience store that provides a wide variety of consumable products. The FamilyMart Group is composed of 23 companies including FamilyMart Co., Ltd., 11 subsidiaries, and 11 affiliates. Centered at the core of its business is a network of 15,789 convenience stores (as of the end of February in 2010) in Japan and other countries. The store in this study was on campus at Nagoya University. The store was open from 7AM to 11PM. A general view of the retail store is shown in Figure 1.

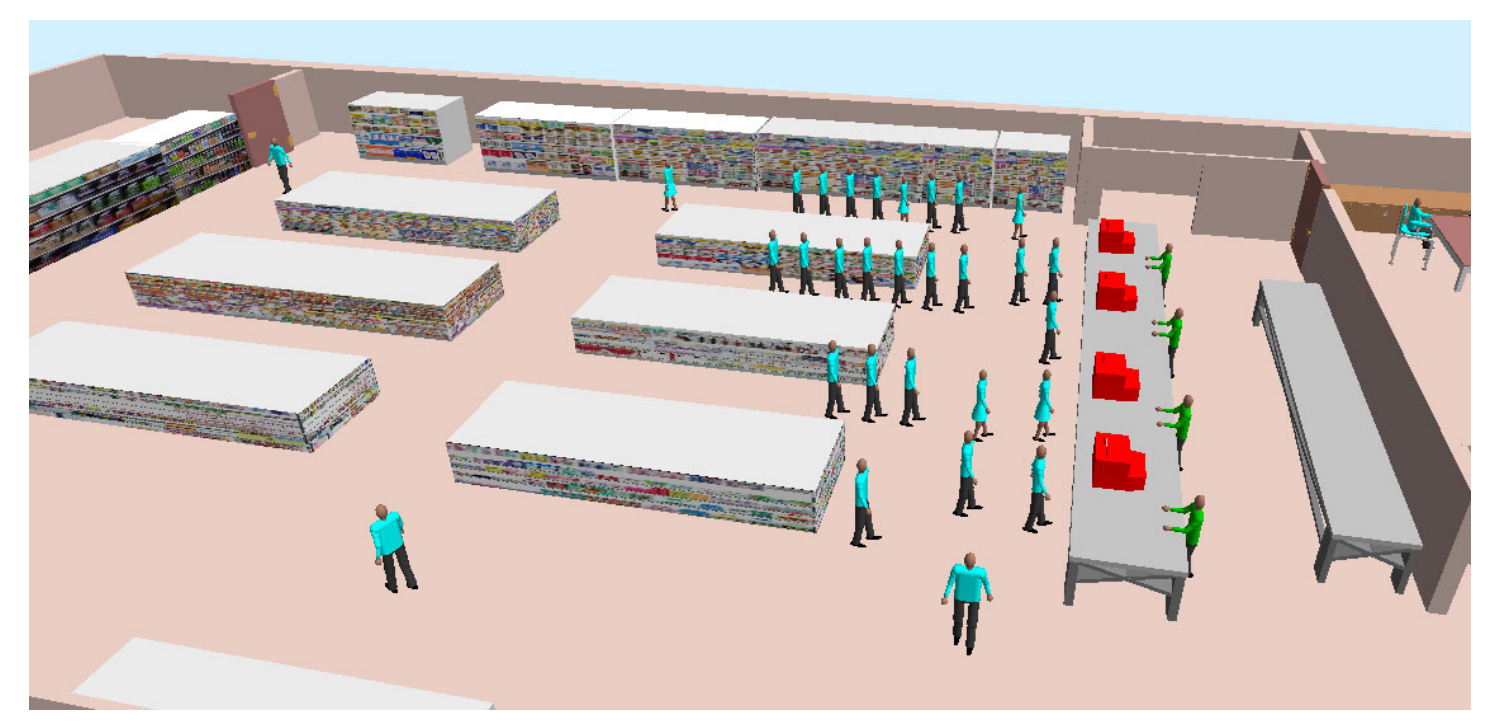

Figure 1: General View of the Retail Store

Recently, operations at the convenience store have been overly complicated. There are 170 types of operations for clerks in the store, and the operations are defined by the manual for FamilyMart, which is divided into 10 classes: (1) service at check-out counter, (2) straightening up the store, (3) order, (4) mag- 


\section{Miwa and Takakuwa}

azines and newspapers, (5) fast food, (6) service, (7) the Fami-Port service, (8) cleaning and maintenance, (9) sorting sales slips, and (10) emergencies. In this store, we collected data on operation frequency and time. The contents of the operations in each period of time are illustrated in Table 1.

Table 1: Operations at the Retail Store

\begin{tabular}{|c|c|c|c|}
\hline $\begin{array}{l}\text { Period of } \\
\text { time }\end{array}$ & Operations of selling goods & Indirect operations & Operations at the cash desk \\
\hline $\begin{array}{c}\text { 7:00-13:00 } \\
\text { (Open) }\end{array}$ & \begin{tabular}{|l|} 
Disposing waste (at 8:00) \\
Receiving, checking, and displaying goods (at 10:00) \\
Displaying goods at special space \\
Preparing Oden \\
Preparing and displaying Chinese-style steamed bun \\
Preparing and displaying deep-fried food
\end{tabular} & $\begin{array}{l}\text { Cleaning the floor } \\
\text { Replenishing supplies } \\
\text { Disposing trash in a store } \\
\text { Controlling humidifying utensil }\end{array}$ & $\begin{array}{l}\text { Counting and taking over at } \\
\text { the cash desk (at around } \\
10: 00 \text { ) }\end{array}$ \\
\hline $\begin{array}{l}\text { 13:00-18:00 } \\
\quad \text { (Open) }\end{array}$ & $\begin{array}{l}\text { Disposing waste (at 15:00) } \\
\text { Receiving, checking, and displaying goods (at 16:00) } \\
\text { Receiving, checking, and displaying newspapers } \\
\text { Displaying goods at special space } \\
\text { Preparing Oden } \\
\text { Accepting home parcel delivery } \\
\text { Preparing and displaying Chinese-style steamed bun } \\
\text { Preparing and displaying deep-fried food }\end{array}$ & $\begin{array}{l}\text { Cleaning the floor } \\
\text { Replenishing supplies } \\
\text { Controlling humidifying utensil }\end{array}$ & $\begin{array}{l}\text { Counting and taking over at } \\
\text { the cash desk (at around } \\
13: 00 \text { ) }\end{array}$ \\
\hline $\begin{array}{l}\text { 18:00-23:00 } \\
\quad \text { (Open) }\end{array}$ & $\begin{array}{l}\text { Receiving, checking, and displaying goods (at 21:00) } \\
\text { Receiving, checking, and displaying newspapers } \\
\text { Preparing Oden } \\
\text { Preparing and displaying Chinese-style steamed bun }\end{array}$ & $\begin{array}{l}\text { Cleaning the floor } \\
\text { Disposing trash in a store }\end{array}$ & $\begin{array}{l}\text { Counting and taking over at } \\
\text { the cash desk (at around } \\
16: 00 \text { ) }\end{array}$ \\
\hline $\begin{array}{l}23: 00-7: 00 \\
\text { (Closed) }\end{array}$ & $\begin{array}{l}\text { Disposing waste (at 22:00) } \\
\text { Receiving, checking, and displaying goods } \\
\text { Preparing and displaying Chinese-style steamed bun } \\
\text { Replenishing papers/toner for copying machines } \\
\text { Preparing and displaying deep-fried food } \\
\text { Putting price labels } \\
\text { Displaying goods for sales promotion }\end{array}$ & $\begin{array}{l}\text { Cleaning the floor } \\
\text { Preparing deep-frying cookware } \\
\text { Preparing Oden utensil } \\
\text { Preparing coffee makers } \\
\text { Preparing retaining-warmth utensil } \\
\text { Controlling humidifying utensil } \\
\text { Cleaning up the checkout counter } \\
\text { Disposing trash in a store } \\
\text { Preparing returned newspapers }\end{array}$ & $\begin{array}{l}\text { Counting and taking over at } \\
\text { the cash desk (at around 23:00 } \\
, 6: 00)\end{array}$ \\
\hline
\end{tabular}

\subsection{Operation Types}

The 170 types of operations were separated into three categories based on restraint conditions. The three types are as follows:

- Priority operations

- Scheduled operations

- Non-scheduled operations

Priority operations mostly relate to customer service at the check-out counters. Clerks must make it a top priority to conduct these operations. Scheduled operations are the operations scheduled some times on a single day. The main operations are counting and taking over at the cash desk, disposing of waste, and receiving/checking/displaying goods. Non-scheduled operations are the operations done as the situation demands. For example, cleaning the floor and displaying goods in a special space is done as needed. In addition, if Oden and Chinese-style steamed buns are sold out, clerks have to prepare these goods. The major operations of each type are shown in Table 2. The flow of operations is illustrated in Figure 2. Clerks always must check to see whether there are priority operations to be accomplished. The operationtype percentages are as follows: priority operations are $57 \%$, scheduled operations are $24 \%$, and nonscheduled operations are $18 \%$. 


\section{Miwa and Takakuwa}

Table 2: Operation Types

\begin{tabular}{|c|c|c|}
\hline Priority operation & Scheduled operation & Non-scheduled operation \\
\hline $\begin{array}{l}\text { Operations at the } \\
\text { checking counter }\end{array}$ & $\begin{array}{l}\text { 6:00 Counting and taking over at the cash desk } \\
\text { 8:00 Disposing waste } \\
\text { 10:00 Receiving, checking, and displaying goods } \\
\text { Counting and taking over at the cash desk } \\
\text { 13:00 Counting and taking over at the cash desk } \\
\text { 15:00 Disposing waste } \\
\text { 16:00 Receiving, checking, and displaying goods } \\
\text { Counting and taking over at the cash desk } \\
\text { 21:00 Receiving, checking, and displaying goods } \\
\text { 22:00 Disposing waste } \\
\text { 23:00 Counting and taking over at the cash desk }\end{array}$ & $\begin{array}{l}\text { Cleaning the floor } \\
\text { Displaying goods at special space } \\
\text { Replenishing supplies } \\
\text { Disposing trash in a store } \\
\text { Preparing Oden } \\
\text { Preparing and displaying Chinese-style } \\
\text { steamed bun } \\
\text { Preparing and displaying deep-fried food } \\
\text { Controlling humidifying utensil } \\
\text { Disposing trash outside a store } \\
\text { Cleaning up the checkout counter } \\
\end{array}$ \\
\hline
\end{tabular}

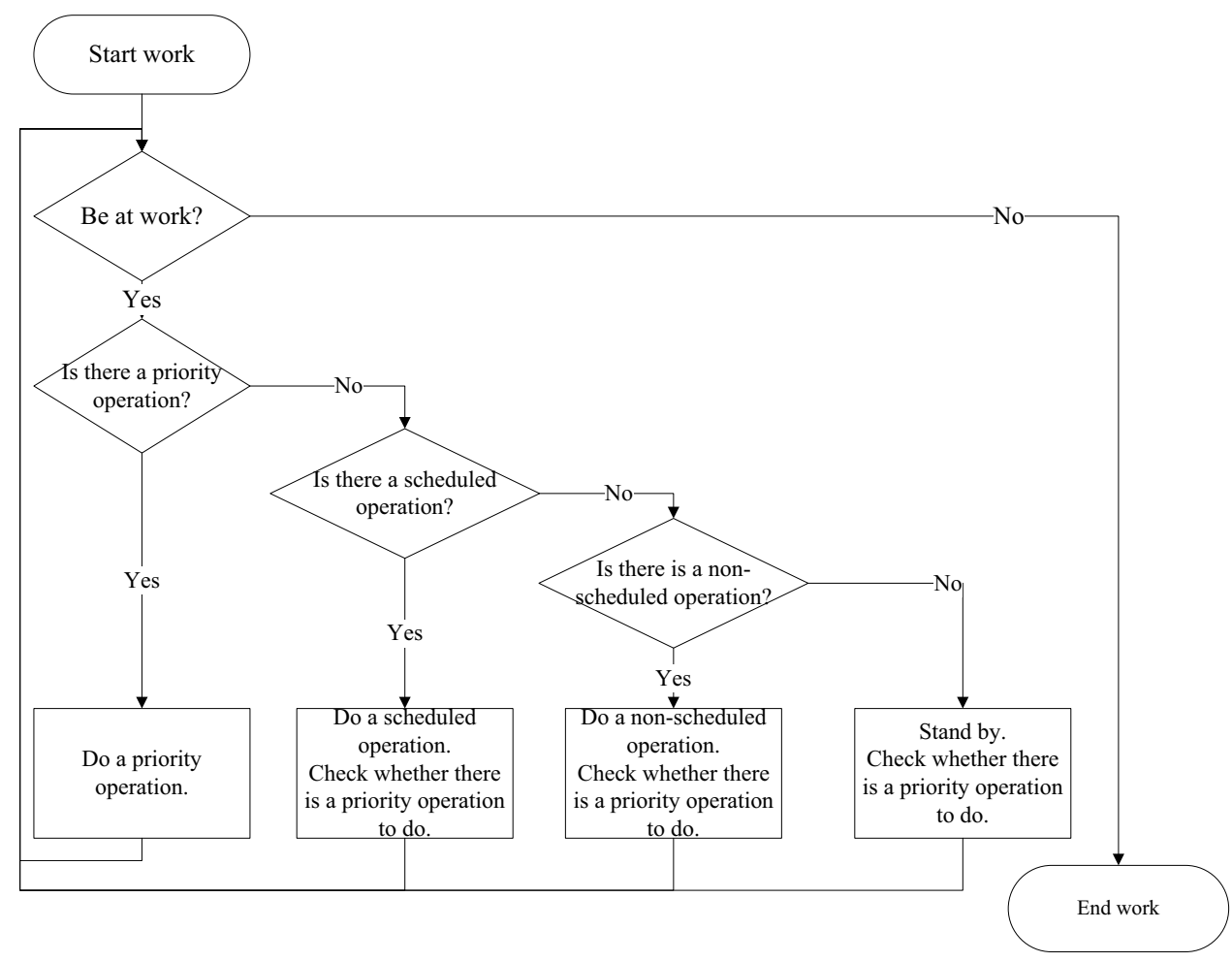

Figure 2: Flow of Operations

\subsection{Staffing Schedule}

The staff schedule at the store was determined by the store manager, who has the necessary experience and intuition. Such choices are not easy because they require both minimizing total personnel expenses and increasing satisfaction for customers through immediate service.

\section{PROCEDURES FOR SEEKING AN OPTIMAL STAFF SCHEDULING SOLUTION}

\subsection{Procedures}

The objective in this study was to minimize daily total working time while satisfying a certain customer service level via operations at the check-out counter. One performance measure at the retail store is ser- 
vice level, defined as the average wait time per hour. The service level target is set after performing the simulation with OptQuest. In the procedure, constrained optimization is used because the service level target is a constraint. The procedures for seeking the optimal solution can be itemized as follows:

[Step1] Collecting required data for staffing problems during each 24-hour period.

[Step2] Performing work loading using total working time during each 24-hour period.

[Step3] Formulating and solving the associated IP model to obtain a set of numbers of clerks for each 24-hour period.

[Step4] Building a simulation model with the initial solution obtained by performing Step 2.

[Step5] Performing simulation with OptQuest using the initial solution obtained by performing Step 3 and Step 4. Obtaining a better feasible solution by modifying the constraints.

[Step6] Determining the optimal set of numbers of clerks during each 24-hour period. Comparing performance figures including the total daily personnel expenses associated with potential solutions in all possible scenarios.

\subsection{Integer Programming Model}

The problem is to determine the optimal number of clerks necessary to conduct the required operations. The overall objective is to minimize daily total working time. The constraints can be formulated as the expected number of operations at each time interval - for instance, one hour or six hours. An integer linear programming problem is a linear program in which all of the variables are restricted to integer values (Ignizio and Cavalier 1994). The problem in this study is to determine the optimal number of clerks $\left(x_{i j}\right)$ while taking into consideration the amount of operations; that is, the number of clerks for each hour required during each total working time. The objective is to minimize the total daily working hours. Then, some assumptions considering the actual operations are necessary: (1) the priority operations should be done immediately, and (2) all operations must be done at their assigned time intervals. Then, an IP model can be written as follows:

Find $x_{i j}$ so as to

minimize

$$
\sum_{i=1}^{I} \sum_{j=1}^{24} x_{i j}
$$

subject to:

$$
\begin{aligned}
& \sum_{i=1}^{I} x_{i j} \geq m_{j} \\
& \sum_{i=1}^{I} \sum_{j=1}^{6} x_{i j} \geq n_{1} \\
& \sum_{i=1}^{I} \sum_{j=7}^{12} x_{i j} \geq n_{2} \\
& \sum_{i=1}^{I} \sum_{j=13}^{18} x_{i j} \geq n_{3}
\end{aligned}
$$




$$
\begin{aligned}
& \sum_{i=1}^{I} \sum_{j=19}^{24} x_{i j} \geq n_{4} \\
& x_{i j}=(0,1)
\end{aligned}
$$

where

$i=$ clerk index

$I=$ total number of clerks (persons)

$j=$ operation-hour index

$k=6$-hour intervals index

$m_{j}=$ total time required for priority and scheduled operations during $j$ th operation hour (man-hour)

$n_{k}=$ total time required for all operations at $k$ th 6 -hour intervals (man-hour) $(k=1,2,3,4)$.

Decision variables:

$x_{i j}= \begin{cases}1, & \text { Clerk } i \text { is at work during the } j \text { th hour of operation. } \\ 0, & \text { Not at work during the } j \text { th hour of operation. }\end{cases}$

Constraint (2) is a constraint in which priority and scheduled operations for each work-hour $j$ are required in total working time. Based on constraint (3), operations are required at 6-hour intervals in total working time. Constraints (4), (5) and (6) require total working time during each 6-hour interval. An initial optimal solution for personnel planning can be obtained by solving an IP model with these constraints.

\subsection{Data and Simulation Model}

\subsubsection{Simulation Model}

The simulation programs were written in Arena (Kelton, Sadowski, and Sturrock 2007). Figure 3 shows the major flow of the clerks' operations in the simulation model. The proposed model is composed of three major logical subsystems: priority operations, scheduled operations and non-scheduled operations. These include operations at the check-out counters. First, priority operations were characterized based on POS data, which indicates customers' arrival at the check-out counter. Then, scheduled operations and non-scheduled operations were indicated using the associated data. Clerks must complete priority operations. When they are completing scheduled operations and non-scheduled operations, they check the waiting line at the check-out counters at every 0.2 minutes. If there are customers in the waiting line, the clerks must immediately complete the transaction at the checking counter.

The simulation model consists of several parameters. Table 3 represents the list of parameters. Based on our time-study, the frequency and timing of clerk operations were analyzed. The process time had a correlation with the number of purchased items, and a regression analysis was applied to determine the duration of time necessary to scan an item, process customer payments, and bag the items. Each operation was modeled based on several attributes. Arrival time as part of each priority operation was established based on the POS data. The processing times at the check-out counters were adapted as triangular distributions using a regression analysis. The animation model was constructed with the Arena 3D player as shown in Figure 1. 


\section{Miwa and Takakuwa}

\subsubsection{Performance Measures}

The primary performance measures considered in this study are the customer wait times during each hour $\left(A W T_{j}\right)$. In addition, the average time that has passed before the start of the associated scheduled operations $\left(A T P_{j}\right)$ and the number of unfinished operations during 6-hour intervals $\left(N U O_{k}\right)$ are used to represent the degree of achievement of operations on the service level.
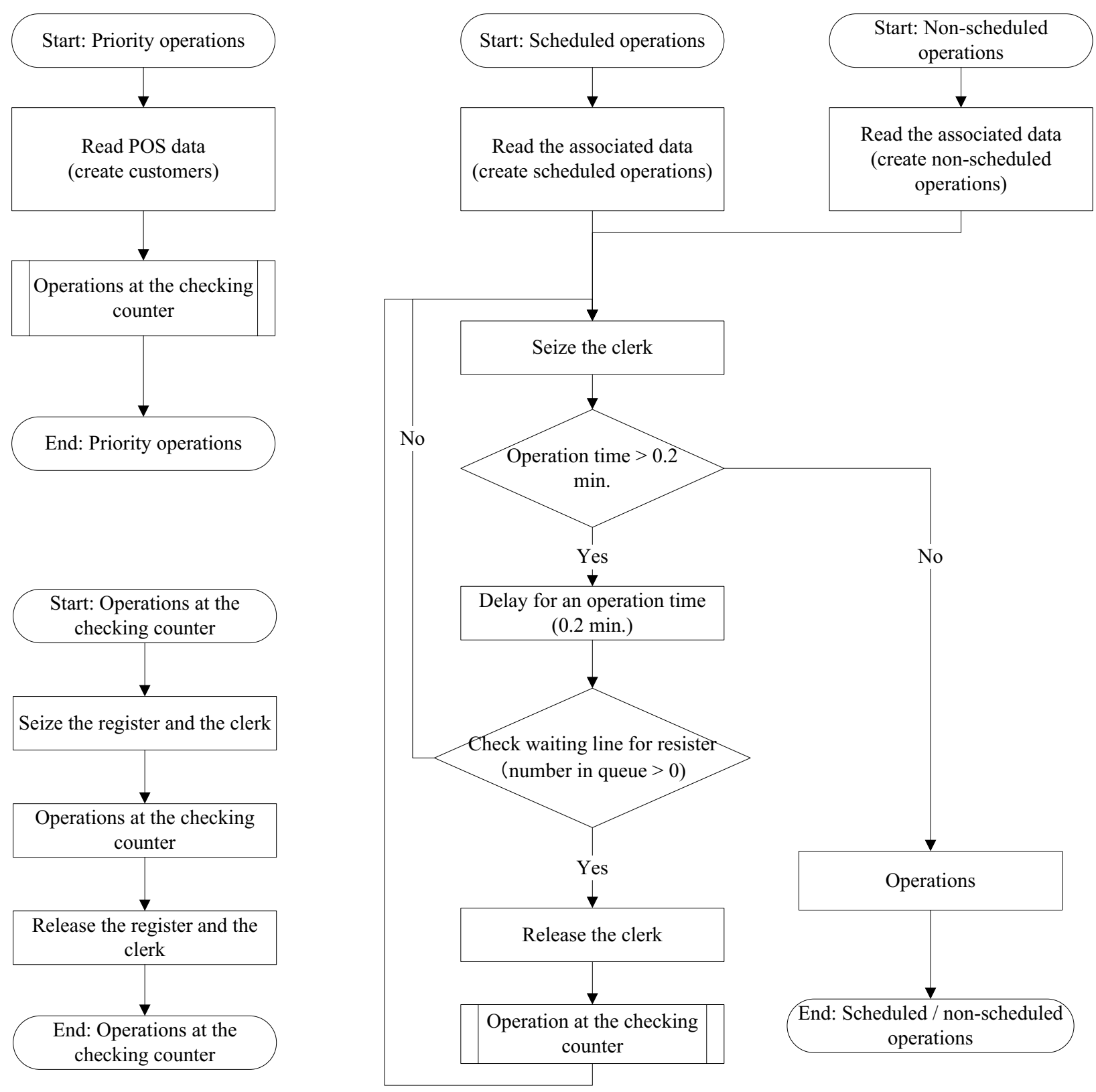

Figure 3: Simulation Logic 


\section{Miwa and Takakuwa}

Table3: Parameters for Performing Simulation

\begin{tabular}{|c|c|c|c|}
\hline \multirow{9}{*}{ Input Data } & \multirow{4}{*}{ Priority operation } & \multirow{3}{*}{ POS data } & Time (hour) \\
\hline & & & Time (minute) \\
\hline & & & Number of purchase \\
\hline & & Process time & TRIA $(7,6.76 n+14.76,6.76 n+14.76+3 * 9.31)$ \\
\hline & \multirow{3}{*}{$\begin{array}{l}\text { Scheduled operation, } \\
\text { Non-scheduled operation }\end{array}$} & Description & \multirow{3}{*}{ See Table 4.} \\
\hline & & Frequency & \\
\hline & & Period of time & \\
\hline & Number of clerks & \multicolumn{2}{|l|}{ See Table 7.} \\
\hline & Number of registers & \multicolumn{2}{|l|}{4} \\
\hline \multirow{3}{*}{ Output Data } & Priority operation & \multicolumn{2}{|c|}{ Average waiting time during each hour period $(A W T)$} \\
\hline & Scheduled operation & \multicolumn{2}{|c|}{ Average time passed to start the associated scheduled operations $(A T P)$} \\
\hline & Non-scheduled operation & \multicolumn{2}{|c|}{ Number of unfinished operations at 6-hour intervals $(N U O)$} \\
\hline
\end{tabular}

\subsubsection{Search for Optimal Solution}

To decide the staffing schedule, we use an optimization program in Arena called OptQuest. The objective of the optimization program is to minimize total working time during a day. The existing total number of clerks was 6. Due to resource limitation and management policies, there are some upper and lower limits to the number of clerks allocated during each hour. The optimization model is as follows: Find $x_{i j}$ so as to minimize the total operations time (man-hours)

$$
\sum_{i=1}^{I} \sum_{j=1}^{24} x_{i j}
$$

Constraints:

$$
\begin{aligned}
& A W T_{j} \leq C_{j} \quad(j=1,2, \ldots, 24), \\
& A T P_{j} \leq D_{j} \quad(j=1,2, \ldots, 24), \\
& N U O_{k}=0 \quad(k=1,2,3,4),
\end{aligned}
$$

Variables:

$$
x_{i j} \quad(j=1, \ldots 24) \text {, }
$$

where

$A T P_{j} \quad$ : Average time that has passed before the start of the associated scheduled operations since the beginning of the assigned operation hour (min.),

$A W T_{j} \quad$ : Average wait time for priority operations during the $j$ th operation hour (min.),

$C_{j} \quad$ : Customers' allowable average wait time for priority operations during $j$ th operation hour (min.),

$D_{j} \quad$ : Permissible delay before the start of scheduled operations (min.),

$N U O_{k}:$ Number of unattended operations at 6-hour intervals (operations).

\section{APPLICATION}

In this section, the proposed procedure is applied to an actual case. The current total number of work hours is 73 (man-hours). 


\section{Miwa and Takakuwa}

\subsection{Data Collection [Step 1]}

The frequency of operations was determined from the store, and these data were analyzed to build the simulation model shown in Table 4. The expected time to be used for check-out operations based on the POS data is shown in Table 5.

\subsection{Loading Operations per Hour [Step 2]}

The work loading of operations per hour is shown in Figure 4. The total number of working hours is 53 (man-hours).

\subsection{Integer Programming Model [Step 3]}

The integer programming model is formulated, and the resultant solution is obtained as an initial feasible solution. The results are shown in Table 6 . The total number of working hours obtained using the IP model is 47 (man-hours).

Table4: Details of Operations

\begin{tabular}{|c|c|c|c|c|c|c|c|}
\hline \multirow[b]{2}{*}{ Operations } & \multicolumn{4}{|c|}{ Frequency } & \multicolumn{3}{|c|}{ Process Time } \\
\hline & $\begin{array}{l}\text { 23:00- } \\
\text { 7:00(Closed) }\end{array}$ & $\begin{array}{l}\text { 7:00- } \\
\text { 13:00(Open) }\end{array}$ & $\begin{array}{l}\text { 13:00- } \\
\text { 18:00(Open) }\end{array}$ & $\begin{array}{l}\text { 18:00- } \\
\text { 23:00(Open) }\end{array}$ & Min. & Mode & Max. \\
\hline Cleaning the floor & 0 & 2 & 2 & 0 & 0.50 & 1.00 & 35.50 \\
\hline Preparing deep-frying cookware & 2 & 0 & 0 & 0 & 0.50 & 16.00 & 101.00 \\
\hline Preparing retaining-warmth utensil & 1 & 0 & 0 & 0 & 0.50 & 1.00 & 101.00 \\
\hline Preparing humidifying utensil & 0 & 0 & 0 & 0 & 0.50 & 1.00 & 101.00 \\
\hline Preparing Oden utensil & 2 & 0 & 0 & 0 & 0.50 & 8.00 & 55.50 \\
\hline Disposing waste & 0 & 1 & 1 & 0 & 0.50 & 1.00 & 40.50 \\
\hline Receiving, checking, and displaying goods & 2 & 2 & 1 & 1 & 1.00 & 36.90 & 120.00 \\
\hline Receiving, checking, and displaying newspapers & 2 & 0 & 1 & 1 & 0.50 & 1.00 & 24.50 \\
\hline Displaying goods at special space & 0 & 9 & 9 & 0 & 0.50 & 1.00 & 77.50 \\
\hline Replenishing supplies & 0 & 3 & 2 & 0 & 0.50 & 1.00 & 9.50 \\
\hline Disposing trash in a store & 3 & 2 & 0 & 3 & 0.50 & 1.00 & 12.50 \\
\hline Preparing Oden & 0 & 2 & 5 & 2 & 0.50 & 1.00 & 30.50 \\
\hline Accepting home parcel delivery & 0 & 0 & 1 & 0 & 0.50 & 1.00 & 3.00 \\
\hline Preparing and displaying Chinese-style steamed bun & 1 & 3 & 11 & 2 & 0.50 & 1.00 & 25.50 \\
\hline Preparing and displaying deep-fried food & 2 & 7 & 9 & 2 & 0.50 & 1.00 & 24.50 \\
\hline Preparing returned magazines & 0 & 0 & 0 & 0 & 0.50 & 1.00 & 3.00 \\
\hline Displaying goods for sales promotion & 0 & 0 & 0 & 0 & 0.50 & 1.00 & 3.00 \\
\hline Replenishing papers/toner for copying machines & 1 & 0 & 0 & 0 & 1.50 & 2.00 & 26.50 \\
\hline Counting and taking over at the cash desk & 0 & 1 & 2 & 1 & 1.50 & 10.00 & 25.50 \\
\hline Preparing returned newspapers & 1 & 0 & 0 & 0 & 0.50 & 1.00 & 9.50 \\
\hline Preparing coffee makers & 1 & 0 & 0 & 0 & 0.50 & 1.00 & 8.50 \\
\hline Controlling humidifying utensil & 1 & 1 & 1 & 0 & 0.50 & 1.00 & 3.00 \\
\hline Putting price labels & 1 & 0 & 0 & 0 & 5.50 & 6.00 & 10.50 \\
\hline Disposing trash outside a store & 0 & 0 & 0 & 0 & 2.50 & 3.00 & 20.50 \\
\hline Cleaning up the checkout counter & 1 & 0 & 0 & 0 & 0.50 & 2.00 & 12.50 \\
\hline
\end{tabular}




\section{Miwa and Takakuwa}

Table 5: Expected Time for Checking-Operation from POS Data

\begin{tabular}{|l|rrrrrrrrrrrrrrrr|}
\hline \multicolumn{1}{|c|}{ Hour period } & $\mathbf{7}$ & $\mathbf{8}$ & $\mathbf{9}$ & $\mathbf{1 0}$ & $\mathbf{1 1}$ & $\mathbf{1 2}$ & $\mathbf{1 3}$ & $\mathbf{1 4}$ & $\mathbf{1 5}$ & $\mathbf{1 6}$ & $\mathbf{1 7}$ & $\mathbf{1 8}$ & $\mathbf{1 9}$ & $\mathbf{2 0}$ & $\mathbf{2 1}$ & $\mathbf{2 2}$ \\
\hline Number of customers & 30 & 110 & 80 & 178 & 128 & 346 & 137 & 191 & 150 & 199 & 126 & 143 & 96 & 75 & 66.7 & 36 \\
\hline Number of purchased items & 71 & 220 & 151 & 356 & 294 & 798 & 304 & 353 & 306 & 366 & 239 & 337 & 221 & 174 & 156 & 88.7 \\
\hline Total expected time (hours) & 0.4 & 1.1 & 0.8 & 1.9 & 1.5 & 4 & 1.6 & 1.9 & 1.6 & 1.9 & 1.3 & 1.7 & 1.1 & 0.9 & 0.8 & 0.4 \\
\hline Required expected number of registers & 1 & 2 & 2 & 3 & 2 & 5 & 2 & 3 & 2 & 3 & 2 & 2 & 1 & 2 & 2 & 1 \\
\hline
\end{tabular}

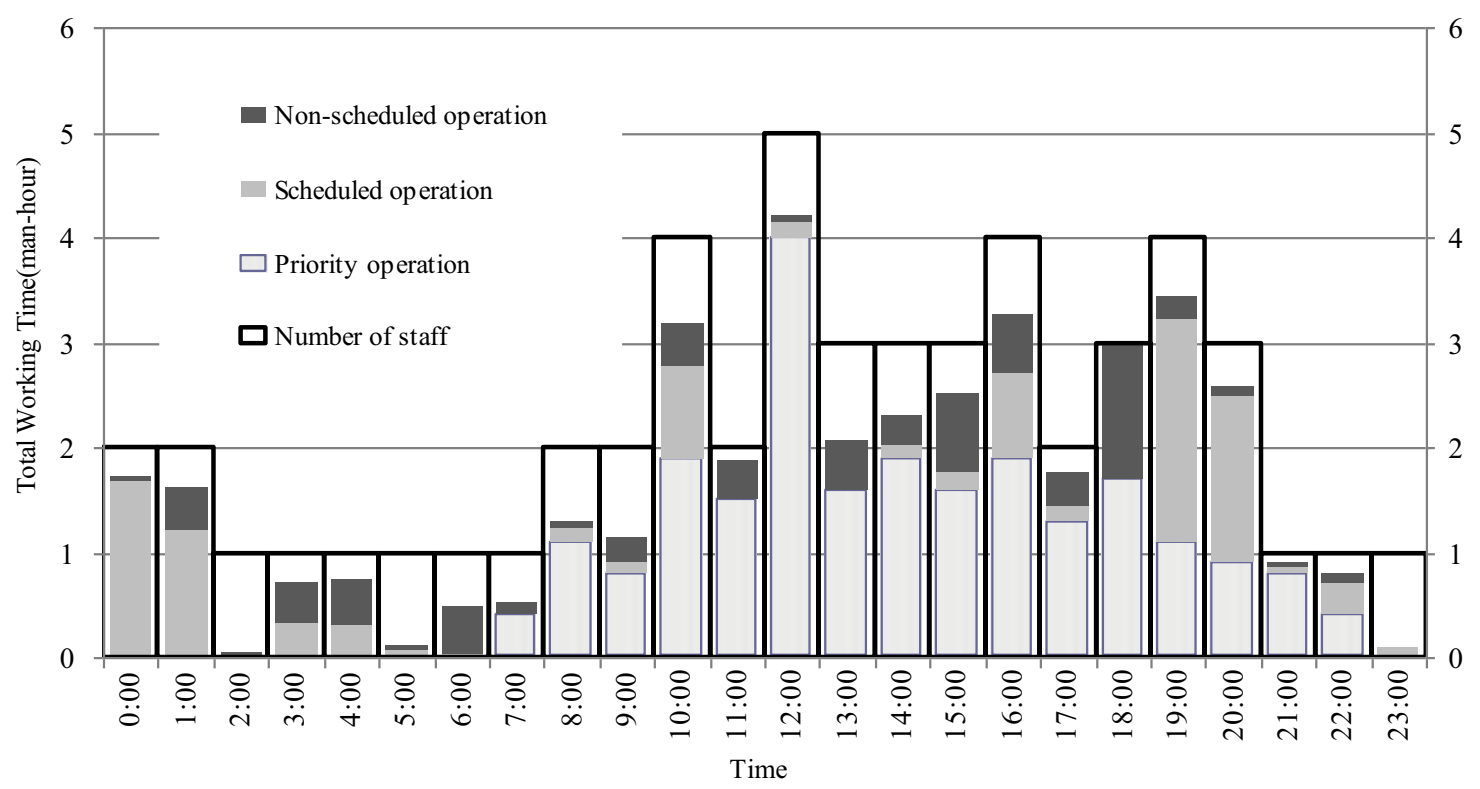

Figure 4: Required Number of Clerks

Table 6: Total Working Time Requirement Based on the IP Model

\begin{tabular}{|c|cccccccccccccccccccccccccc|}
\hline Hour period & 0 & 1 & 2 & 3 & 4 & 5 & 6 & 7 & 8 & 9 & 10 & 11 & 12 & 13 & 14 & 15 & 16 & 17 & 18 & 19 & 20 & 21 & 22 & 23 \\
\hline A & 1 & 0 & 0 & 0 & 1 & 0 & 1 & 1 & 1 & 0 & 1 & 1 & 1 & 1 & 1 & 1 & 1 & 0 & 0 & 1 & 1 & 1 & 0 & 1 \\
B & 0 & 0 & 0 & 0 & 0 & 0 & 0 & 0 & 0 & 0 & 0 & 0 & 1 & 1 & 0 & 0 & 1 & 0 & 1 & 1 & 0 & 0 & 1 & 0 \\
C & 0 & 0 & 0 & 0 & 0 & 0 & 0 & 0 & 0 & 1 & 0 & 0 & 1 & 0 & 0 & 1 & 1 & 0 & 0 & 1 & 0 & 0 & 0 & 0 \\
D & 1 & 1 & 1 & 0 & 0 & 0 & 0 & 0 & 0 & 0 & 0 & 0 & 1 & 0 & 0 & 0 & 0 & 1 & 0 & 1 & 0 & 0 & 0 & 0 \\
E & 0 & 0 & 0 & 1 & 0 & 0 & 0 & 0 & 0 & 0 & 1 & 1 & 0 & 0 & 1 & 0 & 0 & 0 & 1 & 0 & 1 & 0 & 0 & 0 \\
F & 0 & 1 & 0 & 0 & 0 & 1 & 0 & 0 & 1 & 0 & 1 & 0 & 1 & 0 & 1 & 0 & 0 & 1 & 0 & 0 & 1 & 0 & 0 & 0 \\
\hline Total & 2 & 2 & 1 & 1 & 1 & 1 & 1 & 1 & 2 & 1 & 3 & 2 & 5 & 2 & 3 & 2 & 3 & 2 & 2 & 4 & 3 & 1 & 1 & 1 \\
\hline
\end{tabular}

\subsection{Simulation [Step 4]}

Figure 5 shows the results of the simulation for three staffing schedules. In this case, the optimal solution is the "As Is" schedule, which is the one that is actually being used. The work hours under the "Work Loading" model and "IP" model are shorter than under the "As Is" model. However, the results of the simulation indicate that the wait time is longer because the model includes stochastic variation. In addition, the "Work Loading" schedule includes 28.0 unfinished operations, and "IP" model entails 48.6. Hence, these scenarios are not realistic. 


\section{Miwa and Takakuwa}

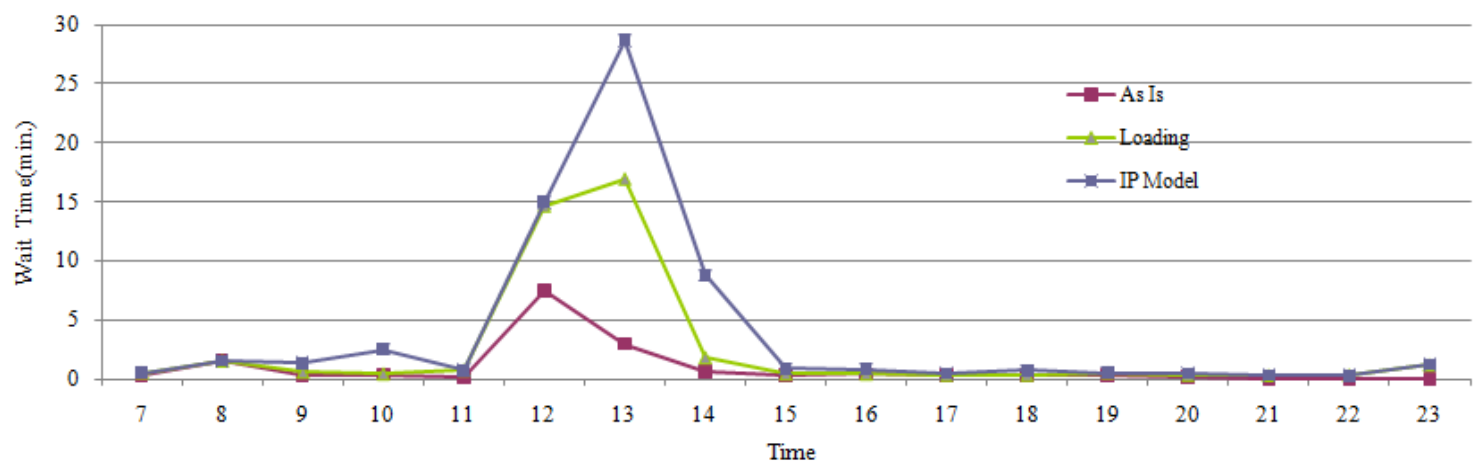

Figure 5: Simulation Results

\subsection{Search for Optimal Solution [Step 5]}

In the next step, the optimal solution is sought by performing a simulation with OptQuest. The constraints are that wait time must be under the "As Is" scenario and that there must be no unfinished operations. OptQuest is an optimization program in Arena that uses a special search algorithm to search for the best solution or a near-best solution. OptQuest combines the metaheuristics of Tabu Search, Neural Networks, and Scatter Search into a single search heuristic (Kleijnen and Wan 2007) to find the best value for one or multiple objective functions.

One major advantage of integrating the simulation model with an optimization program is that the decision variables for the objective functions are not necessarily in the constraints. Based on performance measures like the average wait time, which was generated using the simulation model, OptQuest can evaluate alternative staffing schedules by altering the number of clerks in each time interval subject to given constraints.

The objective of the optimization program is to minimize total working time during a given day. The actual total number of clerks was 6 at the time of the study. Due to resource limitation and management policies, there are some upper and lower limits to the number of clerks on-staff during each hour.

The initial optimization program was executed 1,000 times. Within this timeframe, one thousand simulations were executed, and this graph established the best results found so far as a function of the simulation number runs. After running 1,000 different scenarios, the best scenario was determined to be the 767th, wherein the total working time was 62 (man-hours) for a single day.

\subsection{Optimal Solution [Step 6]}

The optimal solution was obtained by performing a simulation with OptQuest. The optimal solution cut current, actual working hours by $7.5 \%$. The work load under the "IP" model decreased working hours by a total of 20 and improved the solution by 30\%. However, the "IP" model and "Work Loading" model ignored the issue of wait time, and the results showed that there were increased wait times and unfinished operations under these scenarios. The comparisons among the staffing schedules are illustrated in Table 7 and Figure 6.

Table 7: Staffing Schedule

\begin{tabular}{|c|cccccccccccccccccccccccccc|c|}
\hline Hour period & 0 & 1 & 2 & 3 & 4 & 5 & 6 & 7 & 8 & 9 & 10 & 11 & 12 & 13 & 14 & 15 & 16 & 17 & 18 & 19 & 20 & 21 & 22 & 23 & Total \\
\hline As Is & 1 & 1 & 1 & 1 & 1 & 1 & 1 & 2 & 2 & 3 & 4 & 6 & 6 & 5 & 4 & 4 & 4 & 4 & 5 & 4 & 4 & 4 & 3 & 2 & 73 \\
Work Loading & 2 & 2 & 1 & 1 & 1 & 1 & 1 & 1 & 2 & 2 & 4 & 2 & 5 & 3 & 3 & 3 & 4 & 2 & 3 & 4 & 3 & 1 & 1 & 1 & 53 \\
IP Model & 2 & 2 & 1 & 1 & 1 & 1 & 1 & 1 & 2 & 1 & 3 & 2 & 5 & 2 & 3 & 2 & 3 & 2 & 2 & 4 & 3 & 1 & 1 & 1 & 47 \\
OptQuest & 1 & 1 & 1 & 1 & 1 & 1 & 1 & 3 & 4 & 4 & 4 & 4 & 4 & 4 & 4 & 5 & 5 & 3 & 2 & 2 & 3 & 2 & 1 & 1 & 62 \\
\hline
\end{tabular}




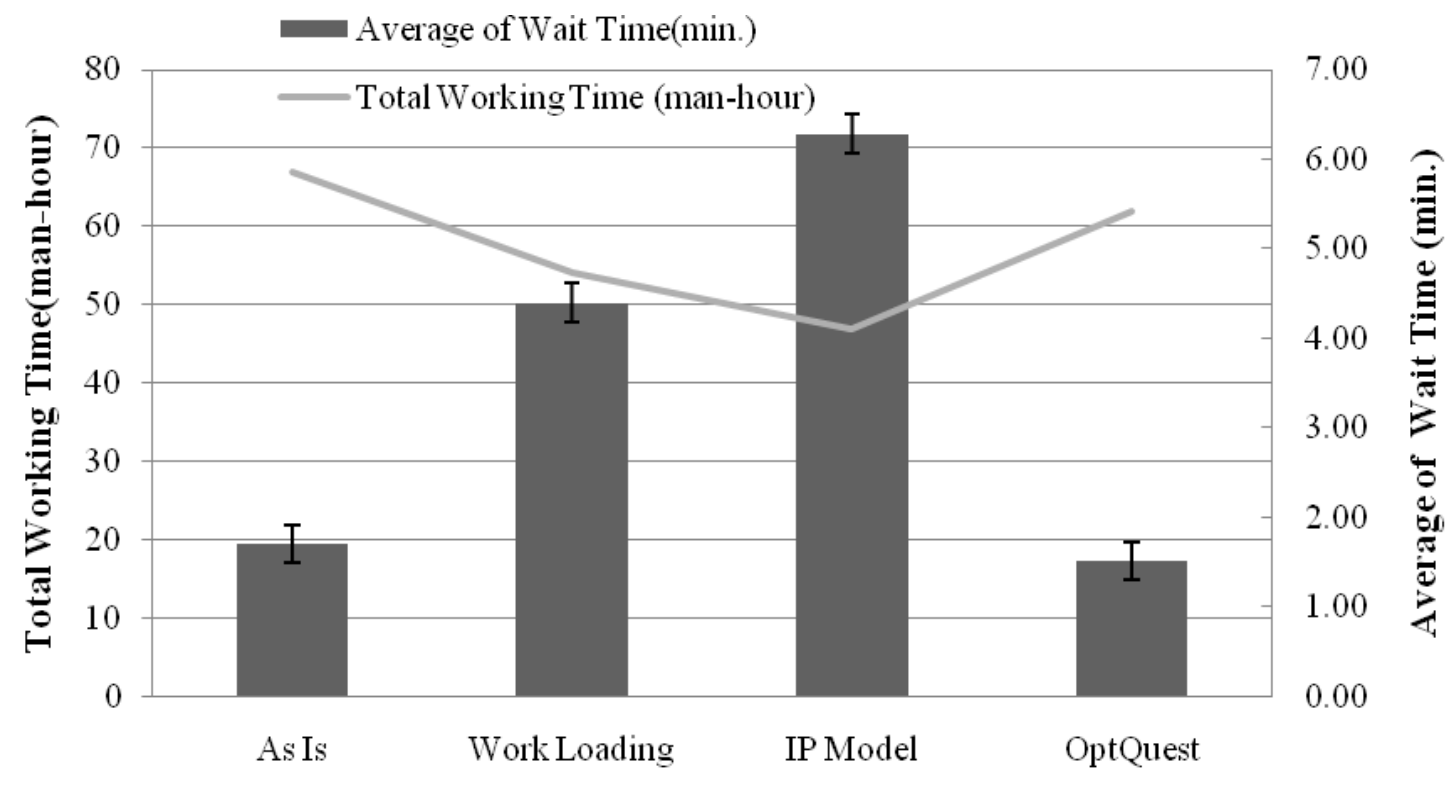

Figure 6: Average Wait time and Total Working Time

\section{CONCLUSIONS}

A simulation modeling procedure for a retail store was proposed to determine the optimal number of clerks taking into account operation types, operation frequency, and staff scheduling. The procedure was designed to determine the optimal number of the clerks as necessary given the frequency of the operations involved.

In the procedure, work loading was performed during each 24-hour period in the first stage. Then, integer programming was used to obtain an initial feasible solution. Then, simulation experiments were performed together with OptQuest, and optimal solutions were obtained. The initial solution was obtained by solving the integer programming problem, and wait time was evaluated by performing the simulation.

The proposed procedure was used for the actual case. It has been shown that staffing problems can be solved easily and effectively in a real-life situation.

\section{ACKNOWLEDGMENTS}

The authors wish to express their sincere gratitude to the FamilyMart Company for their cooperation in allowing us to conduct this research. Special thanks should be expressed to Mr. Ueda and Mr. Abe of FamilyMart Corporation in supporting this research effort. This research was supported by a Grant-in-Aid for the Asian CORE Program of the Japan Society for the Promotion of Science (JSPS).

\section{REFERENCES}

Ignizio, J. P. and T. M. Cavalier. 1994. Linear programming. Englewood Cliffs, New Jersey: PrenticeHill, Inc.

Kelton, W. D., R. P. Sadowski, and D. T. Sturrock. 2007. Simulation with ARENA. 4th ed. New York, NY: McGraw-Hill Co, Inc.. 
Kleijnen, J. P. C. and J. Wan. 2007. Optimization of simulated systems: OptQuest and alternatives. Simulation Modelling Practice and Theory 15: 354-362.

Miwa, K. and S. Takakuwa. 2008. Simulation modeling and analysis for in-store merchandizing of retail stores with enhanced information technology, In Proceedings of the 2008 Winter Simulation Conference, ed. S. J. Mason, R. R. Hill, L. Monch, O. Rose, T. Jefferson, and J. W. Fowler, 1702-1710. Piscataway, New Jersey: Institute of Electrical and Electronics Engineers, Inc.

Tajima, Y. 2001. In-store Merchandizing. Tokyo: Business Sha Co. Ltd. (in Japanese)

Takakuwa, S. and T. Okada. 2005. Simulation analysis of inbound call center of a city-gas company. In Proceedings of the 2005 Winter Simulation Conference, ed. M. E. Kuhl, N. M. Steiger, F. B. Armstrong, and J. A. Joines, 2026-2033. Piscataway, New Jersey: Institute of Electrical and Electronics Engineers, Inc.

Takakuwa, S. and A. Wijewickrama. 2008. Optimizing staffing schedule in light of patient satisfaction for the whole outpatient hospital ward, In Proceedings of the 2008 Winter Simulation Conference, ed. S. J. Mason, R. R. Hill, L. Monch, O. Rose, T. Jefferson, and J. W. Fowler, 1500-1508. Piscataway, New Jersey: Institute of Electrical and Electronics Engineers, Inc.

Wijewickrama, A and S. Takakuwa. 2004. Simulation analysis of patient flows and staffing schedules in an outpatient department, Sri Lankan Journal of Management 9(3\& 4):111-127.

\section{AUTHOR BIOGRAPHIES}

KANNA MIWA is Associate Professor at the School of Commerce at Nagoya Gakuin University in Japan. She received her B.Sc. and M.Sc. degrees in Economics from Nagoya University in 2000 and 2003 respectively. She received her Ph.D. from the Graduate School of Economics and Business Administration at Nagoya University in 2006. Her research interests include the optimization of logistics, supply chains, and manufacturing systems. Her email is $<k m i w a @ n g u \cdot a c \cdot j p>$.

SOEMON TAKAKUWA is Professor at the Graduate School of Economics and Business Administration at Nagoya University in Japan. He received his B.Sc. and M.Sc. degrees in industrial engineering from Nagoya Institute of Technology in 1975 and Tokyo Institute of Technology in 1977, respectively. His Ph.D. is in industrial engineering from The Pennsylvania State University. He holds a Doctorate of Economics from Nagoya University. He holds a P. E. in Industrial Engineering. His research interests include the optimization of manufacturing and logistics systems, management information systems and simulation analysis of these systems including in the context of hospitals. He prepared the Japanese editions of both Introduction to Simulation Using SIMAN and Simulation with ARENA. He concurrently serves as the senior staff of Department of Hospital Management Strategy and Planning at Nagoya University Hospital, too. His email is <takakuwa@soec. nagoya-u.ac.jp>. 